\title{
Pattern of Mandibular Fractures in Western Region of Nepal
}

\author{
Adhikari RB, ${ }^{1^{*}}$ Karmacharya $A,{ }^{1}$ Malla $N^{1}$ \\ ${ }^{1}$ Department of Dental Surgery, Manipal College of Medical Sciences, Pokhara, Nepal
}

\section{*Corresponding Author: \\ Dr. Ram Bhakta Adhikari, Lecturer \\ Manipal Teaching hospital, Pokhara, Nepal \\ Email: dradhikari7@hotmail.com}

\section{Citation}

Adhikari RB, Karmacharya A, Malla N. Pattern of mandibular fractures in western region of Nepal. Nepal Journal of Medical Sciences. 2012; 1(1): 45-48.

\begin{abstract}
Background:

Mandible and nasal bones are the most prominent part of the facial skeleton and are commonly fractured. Its fractures result in severe loss of function and disfigurement. This study was conducted to evaluate and analyze the pattern of mandibular fractures in Western region of Nepal.

Methods: This hospital based, descriptive, cross sectional study included 120 patients treated in the Department of Dental surgery, Manipal Teaching Hospital, Pokhara, Nepal from $1^{\text {st }}$ August 2008 to ${ }^{\text {st }}$ December2011. These patients were examined both clinically and radiologically for mandibular fractures. Data concerning age, gender, causes of fracture and sites of fracture were analyzed.
\end{abstract}

Results: The age range was 3-80 years (mean26.3 \pm 13.43 years) and male to female ratio was 1:0.69. Highest frequency was seen in 21-30 years age group. The leading cause of mandibular fracture was road traffic accident $(\mathrm{n}=56 ; 46.6 \%)$, followed by accidental fall from height or tree $(n=28 ; 23.3 \%)$, physical assault $(n=18 ; 15 \%)$, sports injuries $(n=12 ; 10 \%)$, industrial accidents $(n=4 ; 3.3 \%)$ while 2 cases $(1.6 \%)$ were associated with other causes. The most common site was parasymphysis $(n=42$; $35 \%)$ followed body $(n=22 ; 18.33 \%)$, angle $(n=20 ; 16.6 \%)$, condyle $(n=18 ; 15 \%)$ and symphysis $(n=10 ; 8.33 \%)$.

Conclusion: The study reveals that the majority of the patients were young adult male. The most common etiological factor was road traffic accident and commonly fractured site was the parasymphysis.

Keywords: Mandible fracture; etiology; road traffic accidents; pattern

\section{Background:}

$\mathrm{M}$ andible is unpaired and only the mobile bone of the facial skeleton which plays an important role in mastication, speech, and deglutition. Being a prominent bone of the facial skeleton Mandibular fractures are one of the commonest fractures of facial skeleton. ${ }^{1}$ They may occur alone or in combination with other facial injuries. ${ }^{2}$ The pattern of mandibular fractures has been reported in literature from several countries and these statistics vary from country to country and it is clear that some of the variations can be attributed to social, cultural, and environmental factors. Very few published studies are available on the pattern of mandibular fractures in developing country. The main causes of mandibular fractures include: Road traffic accidents (RTA), Interpersonal violence, Accidental falls, Sport injuries, Industrial trauma. ${ }^{3}$ These etiological factors depend upon the geographic conditions, socioeconomic status and cultural characteristics of people. ${ }^{4}$ Road traffic accident is the leading cause of mandibular fracture in third world countries, ${ }^{5}$ interpersonal violence and physical assault is the leading cause in developed countries. ${ }^{6}$ The 
most common causative factor in young adults is the road traffic accident and fall in the younger population. ${ }^{7}$ Age and sex have been cited as important factors that influence the occurrence of mandibular fractures. The highest incidence is seen in the age group 21-30 years. The lowest incidence is observed in the age group above 60 years and below 5 years ${ }^{8}$ recent data indicates 3:1 male: female ratio worldwide. ${ }^{9}$ The most commonly fractured site is the angle followed by the body and parasymphysis. ${ }^{10}$ In adults the most common site of fracture is the mandibular body, whereas the condyle predominates in young children. ${ }^{11}$

In maxillofacial injuries the ratio of mandible to zygomatic to maxillary fracture is 9:4:1.3 Fracture site depends upon the mechanism of injury, magnitude and direction of impact force, prominence of the mandible and anatomy of site. ${ }^{12}$ Facial bones have low tolerance to impact forces. Its resistance to compression is greater but tends to fracture at the site of tensile strain. In addition, it is more sensitive to lateral impact especially the body and ramus. ${ }^{13}$

Recent trends in the management of mandibular fractures are firstly, by inter dental arch bars wiring along with intermaxillary fixation and Gunning splints. Secondly, intermaxillary fixation with osteosynthesis by intrasosseous wiring, circumferential wiring and external Pin fixation. Thirdly, osteosynthesis without intermaxillary fixation by miniplates, non-compression plates, compression plates and lag screws. ${ }^{14}$

The purpose of this study is to evaluate pattern of mandibular fractures in western region of Nepal as the etiology of mandibular fractures is a direct reflection of the social status and society of this particular region.

\section{Methods:}

This descriptive study on pattern of mandibular fracture was conducted on 120 patients of any sex and age group presenting with the features of mandibular fractures in the Department of Dental Surgery, Manipal Teaching, Pokhara, Nepal from $1^{\text {st }}$ August to $1^{\text {st }}$ December 2011. With the consent of the patients, a detailed history was taken and detail clinical examination was done. All the patients suspected of having mandibular fractures were advised to take An Orthopantomogram and postero-anterior view of mandible. Based on history, clinical examination and imaging studies the definitive diagnosis of mandibular fractures was established. The data concerning the study was obtained on preformed Proforma and evaluated and analyzed by SPSS version 12.0.

\section{Results :}

The age of patients at the time of injury ranged from 3-80 years, with a mean age $26.3 \pm 13.43$ years. In most cases the patients were between 21-30 years $(n=39 ; 32.5 \%)$.Only $13.3 \%$ of patients were less than 10 years of age, and $0.8 \%$ were more than 60 years of age(Table 1$)$.

Table 1: Age distribution of mandibular fractures

\begin{tabular}{ccc}
\hline $\begin{array}{c}\text { Age groups } \\
\text { (years) }\end{array}$ & No. of patients & Percentage \% \\
\hline $1-10$ & 16 & 13.3 \\
$11-20$ & 25 & 20.8 \\
$21-30$ & 39 & 32.5 \\
$31-40$ & 23 & 19.1 \\
$41-50$ & 10 & 8.3 \\
$51-60$ & 6 & 5 \\
$60-80$ & 1 & 0.8 \\
\hline Total & 120 & 100 \\
\hline
\end{tabular}

Regarding gender distribution male $(\mathrm{n}=71 ; 59.1 \%)$ predominated the female $(n=49 ; 40.8 \%)$ with male to female ratio 1:0.69. The most common cause of mandibular fractures was RTA $(n=56 ; 46.6 \%)$ followed by accidental fall $(n=28$; $23.3 \%)$, physical assault $(n=18 ; 15 \%)$,sports $(n=12 ; 10 \%)$ while the least involved group was industrial accidents $(\mathrm{n}=4 ; 3.3 \%)$, (Table 2$)$.

Table 2: Distribution of mandibular fractures according to etiology

\begin{tabular}{lcc}
\hline Etiology & $\begin{array}{c}\text { No. of } \\
\text { patients }\end{array}$ & Percentage \% \\
\hline RTA & 56 & 46.6 \\
Fall from height & 28 & 23.3 \\
Physical assault & 18 & 15 \\
Sports & 12 & 10 \\
Industrial & 4 & 3.3 \\
Other causes & 2 & 1.6 \\
Total & 120 & 100 \\
\hline
\end{tabular}


A total of 120 patients with mandibular fracture at different sites were included in the study. The most common site of mandibular fracture was parasymphysis $(n=42 ; 35 \%)$, followed by body $(n=22 ; 18.3 \%)$, angle $(n=20 ; 16.6 \%)$, condyle $(\mathrm{n}=18 ; 15 \%)$, symphysis $(\mathrm{n}=10 ; 8.3 \%)$, ramus $(\mathrm{n}=5$; $4.1 \%)$ and coronoid $(n=3 ; 2.25 \%)$.

\section{Discussion :}

Etiology and incidence of mandibular fractures vary with geographic region, socioeconomic condition, cultural characteristics and era. ${ }^{15}$ In our study the predominant age group having mandibular fractures was 21-30 years; these findings are similar with the results of previous studies. ${ }^{1,3}$

The highest frequency of fractures was seen in age group of 21-30 years. It may because people from these age groups are mostly involved in sports, interpersonal violence industrial works and high speed transportation. In most of the cases, road traffic accident occur in these groups during evening and late night hours under the influence of alcohol. Hilly terrain, poor condition of road, over speeding and overloading may be other contributing factors for RTA.

In developing countries the old aged people are economically dependent on their family. The low frequencies of very young and old age groups are due to the low activities of these age groups. The male to female ratio of 1:0.69 shows that the fracture mandible is commoner in male population in western region the Nepal. This finding is consistent with results of previous studies conducted all over the world. ${ }^{1,2}$ The relatively high number of male to female is due to the fact that male are engaged more in outdoor activities while the female are confined to indoor activities. Previous epidemiological studies reported road traffic accident followed by fall as the leading cause of mandibular fractures in developing countries. ${ }^{1,16}$ However, in developed countries, assaults and interpersonal violence are the leading etiological factors. ${ }^{3,17}$

The most common site of mandibular fracture was the parasymphysis $(35 \%)$ followed by the body (18.3\%), angle (16.6\%) and condyle (15\%). A study has found correlation of road traffic accident with parasymphysis fractures, gunshot injuries with body fractures, fall from height with condylar fracture, assault with facture of angle of mandible and fewer parasymphyseal fractures. ${ }^{17}$

In this study parasymphysis fracture of mandible predominates other sites of the mandible fracture as majority of these fractures were caused by road traffic accidents.

\section{Conclusion :}

The study reveals that the majority of the patients were young adult male (21-30 years), the most common etiological factor was road traffic accident, $46.6 \%$ followed by fall from height, $23.3 \%$ while the most commonly fractured site was the parasymphysis $35 \%$ followed by body, $18.3 \%$.

To reduce the incidence of road traffic accident, precaution like seat belts, speed limits, improvement in condition of road, encouraging the young adult population not to consume alcohol and drugs while driving and strict traffic rules may help to reduce maxillofacial trauma and mandible fracture in western region of Nepal.

\section{References :}

1. Tanaka N, Tomitsuka K, Shionoya K, et al. Aetiology of maxillofacial fracture. Br J Oral Maxillofacial Surg 1994;32:19-21.

2. Muzzafar K. Management of maxillofacial trauma. AFID Dent J 1998;10:18-21.

3. Schon R, Roveda SIL, Carter B. Mandibular fractures in Townsville, Australia: incidence, aetiology and treatment using the 2.0 AO/ASIF miniplate system. $\mathrm{Br}$ J Oral Maxillofac Surg 2001;39:145-8.

4. Ansari SR, Khitab U, Qayyum Z, et al. Retrospective analysis of 268 cases of fractures of mandible. Pak Oral Dent J 2004;24:135-8.

5. Lawoyin DO, Lawoyin JO, Lawoyin TO. Fractures of the facial skeleton in Tabuk North West Armed Forces Hospital. A five year review. African J Med \& Med Sci 1996;25:385-7.

6. Edward TJ, David DJ. Simpson DA, et al .Pattern of mandibular fractures in Adelaide, South Australia. Aust New Z J of Surg 1994;64:307-11.

7. Qudeh MA, Khateeb TA, Bataineh AB, et al .Mandibular fractures in Jordanians: a comparative study between young and adults patients. J Craniomaxillofac Surg 2005;33:103-6.

8. Shah A, Shah AA, Salam A. Maxillofacial fractures: Analysis of demographic distribution in 320 patients. Pak Oral Dent J 2006;26:235-8.

9. Adebayo ET, Ajike OS, Adekeye EO. Analysis of the pattern of maxillofacial fractures in Kaduna, Nigeria. Br J Oral Maxillofac Surg 2003;41:396-400.

10. Ogundare BO, Bonnick A, Bayley N. Pattern of mandibular fractures in an urban major trauma centre. $\mathrm{J}$ Oral Maxillofac Surg 2003;61:713-5.

11. Wison S, Smith JA, Preisch, J, et al . Epidemiology of dental trauma treated in an urban paediatric emergency 
Original Article | Adhikari RB, et al. Pattern of mandibular fracture.

department. Paed Emergency Care 1997;13:12-5.

12. Mwaniki DL, Guthua SW. Occurrence and characteristics of mandibular fractures in Nairobi, Kenya. Br J Oral Maxillofac Surg 1990;28:200-2.

13. Perkin CS, Layton SA. The etiology of maxillofacial injuries \& the seat belt law. Br J Oral Maxillofac Surg 1998;26:353-63.

14. Shah AA, Akhtar MU. Unusual mandibular fractures of very young children and their management at tertiary dental care centres. Pak Oral Dent J 2005;25:135-8
15. Haung RH, Prather J, Indrsano T. An epidemiological survey of facial fractures and concomitant injuries. J Oral Maxillofac Surg 1990;48:926-32.

16. Stylogianni L, Arsenopoulos A, Patrikiou A. Fractures of the facial skeleton in children. Br J Oral Maxillofac Surg 1991;29:9-11.

17. Adi M, Ogden GR, Chisholm DM. An analysis of mandibularfractures in Dundee, Scotland (1977-1985). Br J Oral Maxillofac Surg 1990;28:194-9. 